\title{
Pathology of peroneal muscular atrophy (Charcot-Marie-Tooth disease)
}

\author{
J. TREVOR HUGHES AND BETTY BROWNELL
}

From the Department of Neuropathology, Radcliffe Infirmary, Oxford, and the Burden Neuropathological Laboratory, Frenchay Hospital, Bristol

SUMMARY Four cases of peroneal muscular atrophy (Charcot-Marie-Tooth disease) are describe in which observations were made from the necropsy examination of the central nervous system, th $\widehat{\oplus}_{0}$ peripheral nervous system, and the skeletal muscles. The pattern of nerve degeneration in these various locations is described and the conclusion is drawn that the basis of the disease is a very chronic progressive neuropathy. To the pathological descriptions of previous observers is added the finding of fibrosis affecting the muscle spindles which was present in all four of the cases. The्छ literature of the case reports with necropsy examination is reviewed.

Peroneal muscular atrophy is a slowly progressive familial neuromuscular disease which has frequently been studied by the review of clinical cases examined by muscle biopsy and by electrophysiological techniques applied to peripheral nerve and to muscle. Because of the benign course of the disease, detailed necropsy reports are few, although some of the earliest descriptions of the disease (Virchow, 1855; Friedreich, 1873; Marinesco, 1894; Sainton, 1899) were based on cases examined at necropsy. Descriptions of necropsy findings published in the twentieth century (Déjerine and Armand-Delille, 1903; Marinesco, 1928; Alajouanine, Castaigne, Cambier, and Escourolle, 1967) have been few and deal only with single cases, although there is now a large literature dealing with the clinical aspects of the disease and with the pathological changes as seen in nerve and muscle biopsies. For the systematic assessment of the changes in the central nervous system, peripheral nervous system, and skeletal muscles, full descriptions of necropsies are still required and in this paper we present our findings in four cases.

\section{METHODS}

The clinical history and general necropsy findings in each case will now be described. The pathological examination of the nervous system and muscles of the four cases will be described together later. Thê material available in all four cases was the brain, the whole spinal cord including posterior root gang and samples of muscles from upper and lower lim $B s_{\circ}$ In cases 2, 3, and 4 peripheral nerve trunks were afso available. The cord was examined at 12 or meres levels, including the cervical enlargement, upper ânक lower thoracic, lumbar, and sacral levels. Postemof root ganglia from cervical, lumbar, and sacral le were examined. Sections were stained by the folle $\overrightarrow{3} \overrightarrow{0}$ ing methods: haematoxylin and eosin, haematoxytin and Van Gieson, Weil, Holmes, Nissl, Holzer, and Schofield.

\section{CASE 1}

(A2435) W.J., aged 59 years at death. This man had suffered from weakness and clumsiness of the fee $\overrightarrow{\vec{b}}$ since childhood, and had pes cavus. There was history of a similar neurological condition in his maternal aunt and uncle. When examined in the yea? of his death, he had marked atrophy of the distat musculature of both legs with severe weakness of the peroneal and dorsiflexor muscles. The intrinsicos muscles of both hands were wasted. The ankle reflexes were absent but the other reflexes were normal. There was diminished sensation in hands and feet to vibration, pain, and temperature, but light touch sensibility was normal. He died from a cere brovascular accident.

The general necropsy showed a recent cerebra haemorrhage in the region of the left internap capsule. There was moderate atheroma of the majof 
cerebral vessels and an old softening in the right temporal lobe.

\section{CASE 2}

(A3046) M.J., aged 61 years at death. This man belonged to a family known to have peroneal muscular atrophy. He had generalized muscular weakness with bilateral pes cavus. The reason for his last admission to hospital was a carcinoma of the right mandible, which was excised together with the lymph glands in the right side of the neck. The following day he developed a left hemiparesis and this cerebral complication led to his death in coma 20 days after the operation.

The general necropsy findings included a thrombosis of the right internal carotid artery in the neck caused by the trauma of the neck operation. The brain showed a large haemorrhagic infarct in the territory of the right middle cerebral artery. The resulting brain swelling and herniation were the immediate cause of death.

\section{CASE $3^{1}$}

(A3815) M.K., aged 76 years at death. Since childhood this woman was known to have weakness of both feet with pes cavus and by the age of 40 both legs had become progressively weak and the hands were also involved. There was a strong family history in that her father had pes cavus, five of her nine children had muscular weakness and pes cavus, and several of her grandchildren had pes cavus. Examination at intervals during her life showed weakness and wasting of the small muscles of the hands and feet, and some wasting of the forearm and thigh muscles, mild sensory loss in a glove and stocking distribution, tendon areflexia, and normal plantar responses. To this picture of a chronic neuromuscular disease was added in later life several systemic illnesses. She developed diabetes mellitus with extensive atherosclerosis leading to gangrene of the legs requiring a bilateral amputation at the age of 72 years, and subsequently to myocardial infarction with heart block. She died of a carcinoma of the stomach.

The general necropsy findings included symmetrical wasting of the hands, bilateral above-knee amputations, a carcinoma of the stomach, and coronary artery disease with scars of old myocardial infarctions. The terminal illness was acute bilateral bronchopneumonia. The brain showed extensive

\footnotetext{
1 The inherited neurological disease in case 3 , typical clinically of peroneal muscular atrophy, was complicated by diabetes, malignant disease, and bilateral leg amputations. The authors have considered the possible contributions of these conditions to the pathological changes in the nervous system, but were convinced that the changes in the spinal cord, spinal nerve roots, posterior root ganglia, peripheral nerve, and skeletal muscle were those of peroneal muscular atrophy.
}

arteriosclerotic atrophy with several small old infarcts related to occlusions of small cerebral arteries. Sections revealed further microscopical infarcts, and showed secondary degeneration of the left internal capsule and the pyramid.

\section{CASE 4}

(N8433) S.R., aged 38 years at death. This woman had a history of long-standing weakness and wasting of her hands and feet with pes cavus. Her mother had had a similar neurological disorder. She presented on her last admission with the symptoms and signs of a cerebral tumour. In addition to these, it was noted that the small muscles of the hands and the forearms muscles were weak and wasted. The intrinsic muscles of the feet were also wasted and there was bilateral pes cavus. The ankle reflexes were absent but sensation could not be adequately tested. She died from the effects of her cerebral tumour shortly after admission.

The general necropsy findings included acute bilateral bronchopneumonia. The left cerebral hemisphere contained a large infiltrating oligodendroglioma.

\section{SPINAL CORD, SPINAL NERVE ROOTS, POSTERIOR NERVE ROOT GANGLIA, PERIPHERAL NERVE} (THREE CASES), MUSCLE

The pathological findings in these tissues were similar in all cases, differing only in the severity of the changes. The most advanced degeneration was present in case 3 , while the mildest changes were in case 4.

SPINAL CORD Macroscopically, the only finding was slight atrophy of the spinal cord and the nerve roots.

Microscopically, the moderate atrophy of the spinal cord was confirmed. There was degeneration of the posterior white columns at all levels, more marked in the fasciculus gracilis than in the fasciculus cuneatus (Fig. 1). The corticospinal tracts were normal in all cases except in case 3 in which there was degeneration of the right corticospinal tract at all levels, consequent upon a vascular lesion in the cerebrum involving the left internal capsule. The anterior and posterior spinocerebellar tracts were also normal in all cases, but in cases 1 and 4 the cord showed a peripheral rim of myelin pallor associated with fibrosis of the leptomeninges. This could be distinguished from the spinocerebellar tracts with 


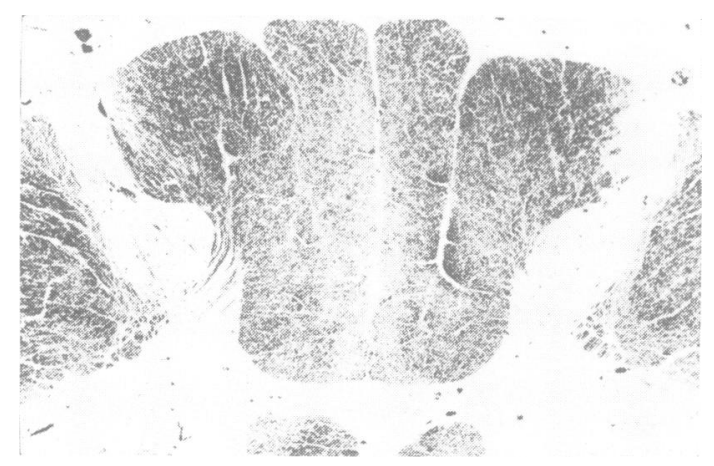

FIG. 1. Case 1. Myelin-stained transverse section of spinal cord at C7 segmental level. Moderate long tract degeneration can be seen in the posterior white columns. Weil, $\times 10$.

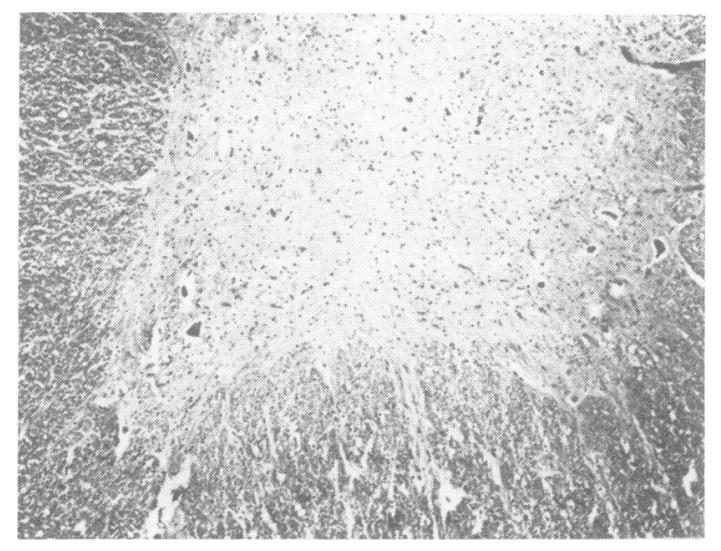

FIG. 2. Case 1. Transverse section of spinal cord at L4 segmental level. There are very few neurone cell bodies in the left anterior grey horn. Haematoxylin and Van Gieson, $\times 40$.

which it did not coincide anatomically. The normal state of the neurones of the Clarke's columns also confirmed the integrity of the posterior spinocerebellar tracts.

The grey matter of the anterior horns was abnormal in all cases (Figs 2, 3). Loss of motor neurones was observed at all levels (Fig. 2), varying from slight in case 4 to very severe in case 3 , but in all cases, most marked in the lumbar and sacral segments. Degenerative changes were also present in motor neurones

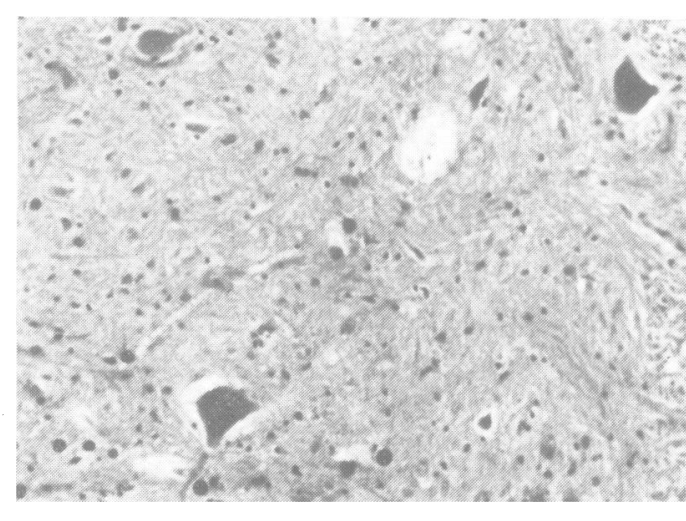

FIG. 3. Case 1. Transverse section of spinal cord a $a \stackrel{\mathbb{Q}}{2}$ L2 segmental level showing detail of the right anteriow grey horn. Groups of glial cells have replaced many of the neurone cell bodies. Nissl, $\times 90$.

(Fig. 3), including shrinkage and pyknosisir (common) and central chromatolysis (rare) Neuronophagia was not seen. Cell loss in $\bar{m}_{0}^{\infty}$ anțerior horns was always accompanied by variable degree of gliosis (Fig. 3), and in cas $2 \vec{b}$ the motor neurones were replaced by lakges numbers of corpora amylacea. No loss neurone cell bodies or degenerative changes were observed in the posterior or intermediso lateral grey horns, or in Clarke's columns.

The spinal nerve roots were abnormal at alp levels, although the changes tended to bes variable. Anterior and posterior roots showe loss of myelinated fibres, degeneration of axons응 and fibrosis, all of which changes were worse in? the anterior than in the posterior nerve roots. Im all four cases, a section of the cauda equina re vealed degeneration and fibrosis which were present in some degree in all the roots seen in the sections.

In all cases the posterior root ganglia were grossly abnormal (Figs 4, 5, 6, 7). There was loss of large myelinated fibres with an increase in fibrous tissue. Ganglion cell bodies were severely depleted (Fig. 4) and the capsule cells (amphicytes) were proliferated around degenera $\rightarrow$ ted neurone cell bodies (Fig. 5). In frozen sec을. tions stained by the Schofield technique and ins paraffin sections obtained by the Holmes' 


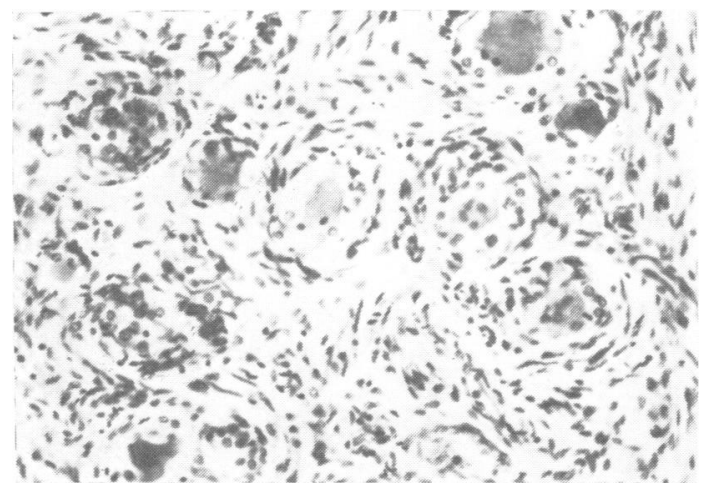

FIG. 4. Case 4. Cervical posterior root ganglion. The photomicrograph shows an increase in fibrous tissue and many degenerated neurone cell bodies. Haematoxylin and eosin, $\times 150$.

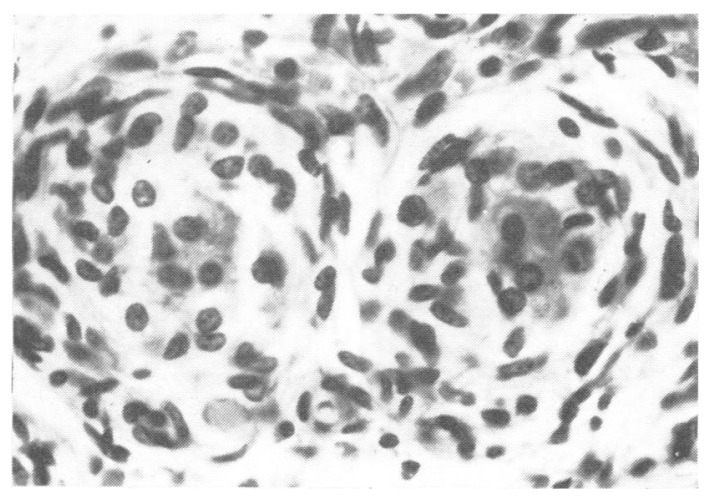

FIG. 5. Case 4. Detail of two examples of 'residual knötchen', the structures formed by proliferation of capsule cells. Haematoxylin and eosin, $\times 375$.

technique (Figs 6, 7), striking changes were observed in the intraganglionic axons, including depletion, fragmentation, budding, and clubshaped or globular endings (Fig. 6). There was also proliferation of very fine unmyelinated fibres, forming spherical tangles (Figs 6 and 7); we considered this phenomenon to be associated with regeneration.

The peripheral nerves examined were samples of large nerve trunks (three cases) from the upper and lower limbs. All showed loss of

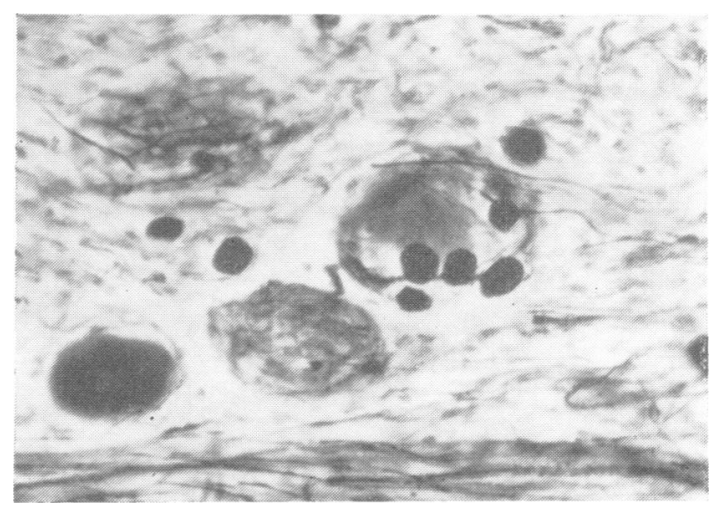

FIG. 6. Case 4. Lumbar posterior root ganglion. Photomicrograph of section stained by silver technique. There is disorder of the ganglionic neurones with whorls of fine regenerated fibres and thickened nerve fibres often with terminal expansion 'clubs'. Schofield, $\times 150$.

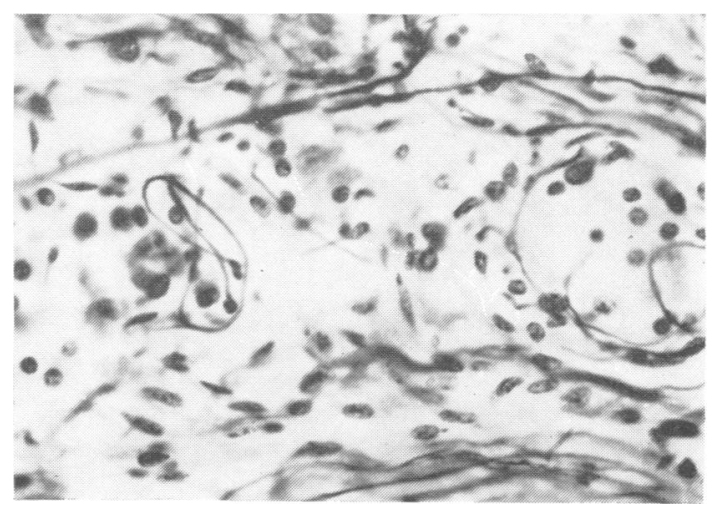

FIG. 7. Case 2. Lumbar posterior root ganglion. Photomicrograph at higher magnification showing detail of abnormal neurones. Small tangles of fine regenerating fibres are present in the picture. Holmes, $\times 160$.

myelinated fibres (Fig. 8, 9) and increase of fibrous tissue in the endoneurium and perineurium, usually very severe. Degenerating axons were present, but not common. These necropsy findings agree with those we have made of biopsies of peripheral nerve which, with the electron microscope, can be examined in greater detail. 


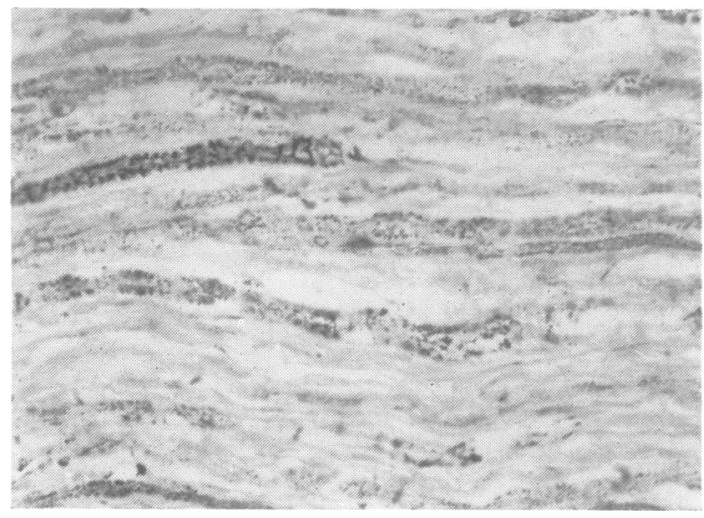

FIG. 8. Case 2. Right femoral nerve. Photomicrograph from myelin-stained longitudinal section. There is gross depletion of myelinated fibres. Weil, $\times 375$.

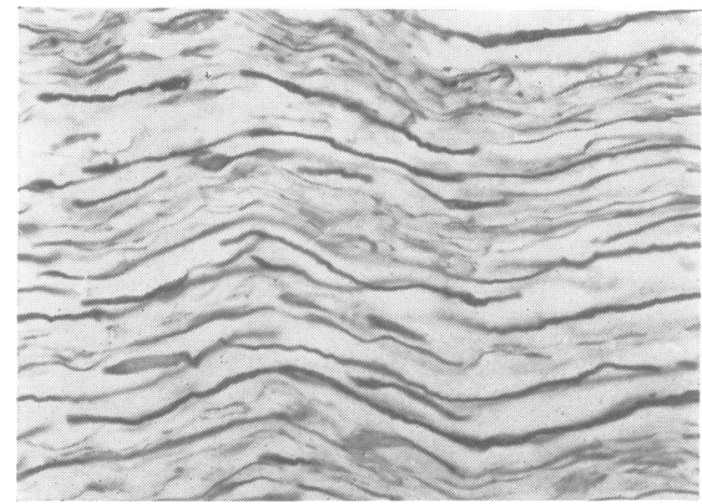

FIG. 9. Case 2. Corresponding silver-stained axonal picture from a section consecutive to that used for Fig. 8. Many of the nerve bundles contain very few axons. Irregularities of axons can be seen. Holmes, $\times 375$.

Muscles examined from all cases showed the groups of atrophic muscle fibres characteristic of slowly progressive denervation (Fig. 10). The atrophy tended to be mild in comparison with the severe changes in the spinal cord and peripheral nerves, and only in the small hand muscles was gross atrophy observed. The degree of atrophy in individual muscle fibres

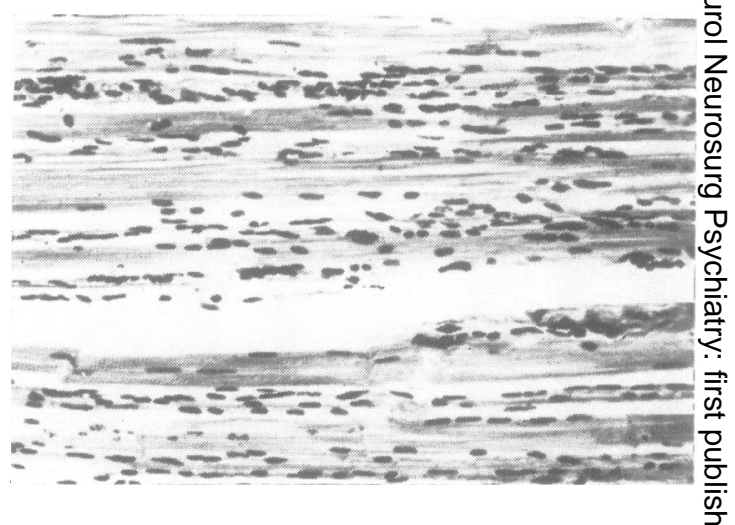

FIG. 10. Case 3. Right sartorius muscle. Photo micrograph of longitudinal section showed atrophied muscle fibres. Haematoxylin and Van Gieson, $\times 150$.

FIG. 11. Case 3. Right sartorius muscle. Detail of severely atrophied muscle fibre. Haematoxylin and Van Gieson, $\times 375$.

was often extreme and sometimes only sarco lemmal nuclei could be seen within the sarco lemmal membrane of a muscle fibre (Fig. 11)응 Only an occasional necrotic muscle fibre was: seen, and very rarely a collection of inflamma 3 tory cells. We were in no doubt that the muscles atrophy was neurogenic in origin, rather than 'myopathic' or 'dystrophic'. In the two cases inf which the tongue was examined (cases 1 and 4$)$ no atrophy was seen. In all four cases, and in every muscle examined, marked pathologica/s changes were seen in the muscle spindles, 


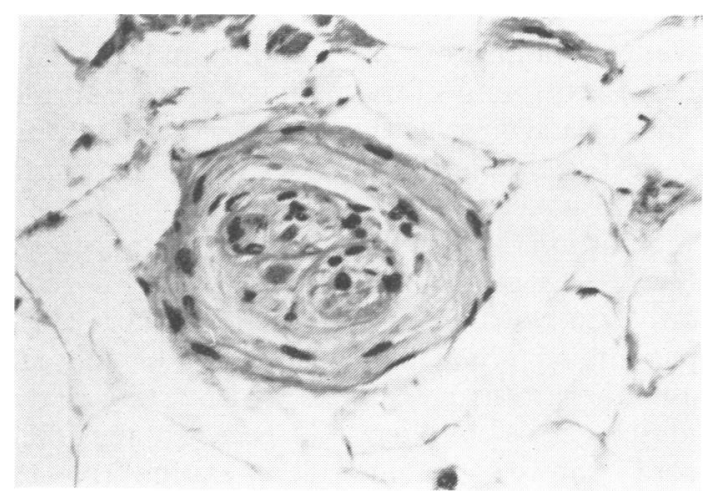

FIG. 12. Case 4. Right thenar muscle. Photomicrograph showing small fibrotic muscle spindle embedded in adipose tissue. Haematoxylin and Van Gieson, $\times 220$

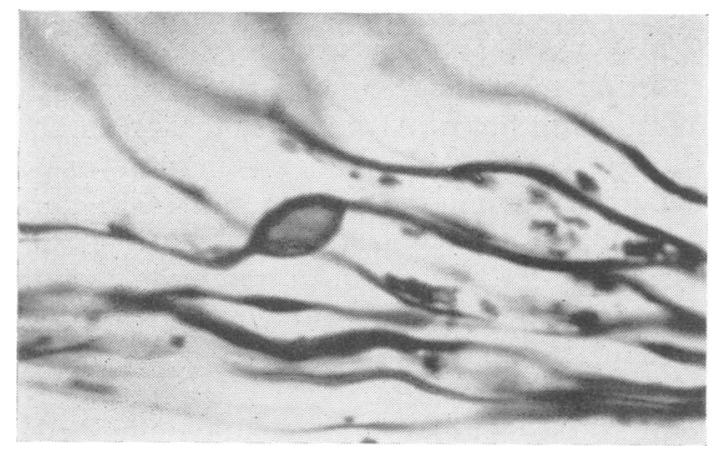

FIG. 13. Case 2. Vastus lateralis muscle. Photomicrograph of silver stained longitudinal section showing a small intramuscular nerve bundle. There are loss of axons, droplet degeneration of axons, and an axonic swelling. Schofield, $\times 1,400$.

affecting almost all the spindles present in the sections, even in muscles in which the extrafusal fibres were not atrophic (Fig. 12). Some muscle spindles were so abnormal that their recognition as muscle spindles was difficult. The muscle spindles showed thickening and fibrosis of the capsule, the septa, and the small blood vessels (Fig. 12). The intrafusal fibres appeared to be reduced in number and in size, and sometimes the entire spindle consisted only of a fibrotic laminated capsule containing one or two com-

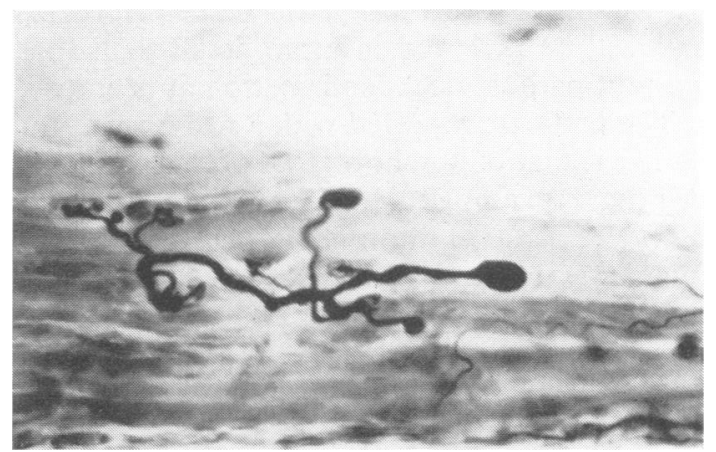

FIG. 14. Case 4. Thenar muscle. There is branching and thickening of the terminal arborization with several growth cones. Schofield, $\times 200$.

pletely atrophic fibres with pyknotic nuclei. Where nerve trunks were seen in relation to spindles, they always showed severe fibre loss and fibrosis. Silver stains for nerve endings and motor endplates (Schofield's technique on frozen sections) were carried out on all the muscle available and always showed abnormalities (Figs 13 and 14). There was severe depletion of axons within the nerve bundles, and occasional droplet degeneration of axons was observed. However, the most striking changes were those which we interpreted as regenerative changes. These consisted of collateral sprouting, beading of terminal fibres, multiplicity of endplates, and the presence of growth cones (Figs 13 and 14). As with the constant presence of abnormal muscle spindles, degenerating and regenerating intramuscular nerve fibres were often observed in muscles which did not show denervation atrophy. Pathological changes were seen in the innervation of the muscle spindles, but it was not certain whether these changes involved only the afferent or efferent nerves, or whether both components of the innervation of the spindles were simultaneously affected.

\section{LITERATURE}

The early reports of peroneal muscular atrophy are scattered throughout many nineteenth century medical journals and this present review may be incomplete. All the early reports found will be mentioned, but those describing cases 
with findings at necropsy will be described first and will be reviewed in more detail than those without pathological confirmation at necropsy.

The first case reported with a necropsy examination is that of Virchow (1855). This was a case of progressive muscular atrophy in a clergyman of 44 years whose father had died with a similar muscle atrophy. At the age of 21 years the patient developed weakness and wasting first of the legs and later of the arms. At necropsy there was a varying degree of atrophy of the skeletal muscles. The peripheral nerves were severely degenerated with scanty nerve fibres separated by an excess of connective tissue. The spinal cord showed posterior column degeneration and there was atrophy of the posterior nerve roots.

Friedreich (1873), in a monograph on progressive muscular atrophy, described his clinical and pathological observations on a sister and brother (cases 2 and 3) who both suffered from a neuromuscular disease. The account of case 2 , in which a necropsy was obtained, is particularly valuable. This woman was 38 years of age at her death. Her disability had begun at the age of 10 years when she began to complain of weakness and wasting of the legs accompanied by occasional pains and twitching of the affected muscles. Later the muscles of the forearm and hands were affected and terminally the muscle of the shoulder girdle. The weakness and atrophy were always most severe in the legs. The sensory examination was normal and there was no sphincter disturbance. Death occurred from bronchopneumonia. At necropsy there was degeneration of the posterior columns, anterior and posterior spinal nerve roots, peripheral nerve trunks, and intramuscular nerves. The skeletal muscles showed atrophy with fibrosis. From the clinical account the brother (case 3) appears to have suffered from a similar neuromuscular disease with a time course closely resembling that seen in the sister.

No relevant family history was obtained in the following five cases.

Marinesco (1894) described the pathological findings in the case of a girl aged 25 years. There was a history of 10 years of progressive weakness and wasting first of the legs and later of the arms and hands. The paresis was accompanied by a painful dysaesthesia with sensory changes and absent reflexes. At necropsy Marinesco found degeneration of the long tracts of the posterio white columns of the anterior and posterior nerve roots, and of the peripheral nerve trunks The skeletal muscles showed denervation atrophy with degeneration atrophy and degeneration of the intramuscular nerve fibres.

Sainton (1899) reported a case with necrops findings (observation 9) in his Paris MD thesis on 'L'amyotrophie type Charcot-Marie'. His patient, an artist, died at the age of 56 years. after progressive weakness and wasting of th $\overrightarrow{\mathrm{E}_{\text {f }}}$ muscles since childhood. At necropsy the spinat cord showed definite degeneration of the posterior columns and of the posterior nerve roots. The grey matter is described as showing 'simple atrophy'. The only posterior roof ganglion examined showed insignificant changes:The peripheral nerve trunks were degenerated and the skeletal muscles showed denervation $\overrightarrow{\text { w }}$ atrophy.

The case of Déjerine and Armand-Delillęㅁํㄹ (1903) was that of a seamstress of 50 years్ suffering from long-standing muscular atrophyer affecting all limbs. At necropsy the spinal cof $\dot{\alpha}_{p}$ showed posterior column degeneration, worseğn the gracile than in the cuneate tracts. The spimap nerve roots and ganglia were not remarkabte $\overrightarrow{0}$ The peripheral nerve trunks were thought to normal but the intramuscular nerves wofer degenerated and there was denervation atrop of the skeletal muscles.

Marinesco (1928) subsequently published a second paper describing a new case with of necropsy examination. The case was that of as 30 year old man who for 10 years had complaineco of weakness and wasting of his legs. Latterly his arms had been affected and he had pains in his legs and trunk. Most of the lower limb reflexes, were lost but his plantar reflexes remained flexor. Death occurred from pulmonary tubercu告 losis. At necropsy the spinal cord showed. posterior column degeneration and depletion of neurone cell bodies from the anterior grey horns: Central chromatolysis was observed in some of the remaining neurone cell bodies. Both the anterior and the posterior nerve roots were atrophied and degenerated. The peripheral nerve trunks were atrophied and fibrotic and thes skeletal muscles showed groups of atrophied. muscle fibres suggesting denervation atrophy The important addition to the findings of pre 
vious necropsy reports was an account of the histological changes in the posterior root ganglia. The neurone cell bodies here were diminished in numbers and where a perikaryon was absent the satellite cells had proliferated to form a 'nodule residuel'.

The most recent case reported with a description of the findings at necropsy is that of Alajouanine et al. (1967), but unfortunately only the brain and the cervical region of the spinal cord were examined. The case concerned a woman who was 80 years of age at the time of her death. She had suffered from weakness and wasting of the lower limbs since the age of 7 years and was diagnosed at the age of 16 years by Professor Charcot at the Hospice de la Salpetrière. The main finding in the brain was a degeneration of the optic nerves and tracts. The spinal cord showed posterior column degeneration, anterior and posterior spinal root atrophy, and depletion of neurone cell bodies from the anterior grey horns. Although it was stated that the spinocerebellar tracts were degenerated, the neurone cell bodies of Clarke's column were said to be normal.

These seven reports contain most of the observations on the pathological findings in Charcot-Marie-Tooth disease. Two other reports which are often quoted cannot be accepted.

The report of Oppenheimer (1855) described three cases all suffering from progressive muscular weakness and in one case (case 21) there was a strong family history, in that a similar disorder affected one brother, three male cousins and two uncles. The case was that of a boy who, at the age of 11 years, had developed weakness and wasting of all his limbs leading to his death at the age of 15 years. The necropsy showed fatty degeneration of the skeletal muscles but no changes in the spinal cord or in the spinal nerve roots. Peroneal muscular atrophy seems an unlikely diagnosis in this case which from the details available was probably a case of muscular dystrophy.

The case of Pette (1924) is also questionable as a case of peroneal muscular atrophy. This 71 year old merchant had a history of chronic alcoholism and may have had syphilis at the age of 20 years. There was weakness and wasting of the limbs but this had been present for only 15 years and began suddenly with a painful swelling of the limbs.

Other case reports which lack descriptions of the necropsy findings deserve mention. The case of Aran (1855) is probably the earliest in the literature. Aran, in a report dealing with three cases of progressive muscular atrophy, described a case (case 1) with a family history. A farmer of 28 years gave a history that two of his aunts had died at an advanced age with generalized muscular atrophy. His own disability had presented 10 years previously with weakness in the right leg. Eight years later the left leg was noticed to be affected and then some months later the right arm. The report mentions weakness and muscle atrophy but there are no observations on the reflexes and no comment on the sensory examination. The clinical picture and the family history suggest peroneal muscular atrophy, although some important clinical observations are lacking.

Bamberger (1860) described two brothers aged 24 and 16 years who developed muscle weakness one at the age of 7 and the other at the age of 11 years. There was a strong family history in that a paternal aunt had died with weakness and wasting of the limbs and the sister of the two boys had a painful wasting condition of the arms. The reported disabilities on the mother's side of the family may not have been relevant. In the two boys the muscle weakness and wasting became extreme in the legs and also affected the arms. No necropsies were obtained.

The famous report of Charcot and Marie (1866) is of historical importance because their clinical description of five cases drew attention to the disease which in France is still called 'Maladie de Charcot-Marie'. In the same year Tooth (1886) published a very full account of the clinical findings in several cases whose study formed the basis of a Cambridge University thesis. These cases were later reported in a medical journal (Tooth, 1888).

Towards the end of the nineteenth century there are many clinical accounts of which considerations of space prevent more than a brief mention here. Eulenburg (1871) described three cases in sisters and Eichhorst (1873) published a large study of a family in whom he had studied 10 cases spanning three generations of the family. The account of Osler (1880) described a family with 13 affected members showing a 
dominant mode of inheritance. Schultze (1884) described three cases in siblings and Ormerod (1884) three cases in two brothers and their father and another extensive family tree with several affected members was reported by Herringham (1889).

\section{DISCUSSION}

In our four cases, the only relevant tract degeneration seen in the central nervous system can be explained as a secondary Wallerian degeneration from a disease process primarily affecting the posterior root ganglia and the peripheral nerves. Moderate fibre degeneration in the posterior columns was present in all cases and this affected the gracile more than the cuneate fasciculi. This degeneration corresponded in intensity to the degeneration found in the posterior roots. It was less than the degeneration seen in severe tabes dorsalis, in Friedreich's ataxia, and above a complete cord transection.

The other constant feature seen in the spinal cord was loss of motor neurone cell bodies from the anterior horns. This loss was less severe than that seen in motor neurone disease and had features such as central chromatolysis not seen in that disease, while neuronophagia (found regularly in motor neurone disease) was not observed. These differences from motor neurone disease may indicate a difference in the progression of the disease in an individual neurone. The disease may begin in the cell body in motor neurone disease, whereas in peroneal muscular atrophy the axon outside the central nervous system may be first affected. Other differences may be attributable to the very chronic course of peroneal muscular atrophy. The very large numbers of corpora amylacea in the anterior horns indicate a degeneration with a long time course.

The histological examination of the peripheral nervous system was the most productive. The spinal nerve roots both anterior and posterior consistently showed degeneration. This was less in the posterior roots than is seen in tabes dorsalis and in Friedreich's ataxia, and less in the anterior roots than is seen in motor neurone disease. This difference of severity may be due to the extreme chronicity of peroneal muscular atrophy. Death was always due to some other incidental condition and the disease may not become fully manifest as do the other fatal $z$ neurological degenerations.

The posterior root ganglia always showed extensive changes with loss of neurone cell $\stackrel{c}{0}$ bodies and degenerative changes in those 0 remaining. The proliferation of the capsule cells $\stackrel{\infty}{\leftarrow}$ surrounding the vacant space of a cell body is conspicuous and similar to that seen in Fried- $\frac{0}{2}$ reich's ataxia. The peripheral nerves always showed severe degeneration with fibrosis which $\stackrel{\vec{\rho}}{\mathcal{2}}$ seemed out of proportion both to the clinical $\bar{C}$ disability and to the secondary degeneration $\frac{\overline{ }}{\bar{N}}$ seen in the spinal cord and skeletal muscle. Why this disproportion exists requires explanation. Perhaps in this disease we see in the peripheral $\%$ nerve trunk a summation of neurological $\overrightarrow{0}$ degenerations. Here is combined all the afferent $\vec{\overrightarrow{ }}$ degeneration seen in Friedreich's ataxia and the $\stackrel{\omega}{\omega}$ efferent degeneration seen in motor neurone disease. We know that the afferent fibres make? up the bulk of peripheral nerve trunks even of those nerves which are termed 'motor'. It seems likely that the degeneration of all these fibre $\vec{\infty}+\infty$ results in the excessive fibrotic atrophy of tre peripheral nerves seen in this condition. TI degeneration of the peripheral nerves is worse than in Friedreich's ataxia (where the efferent 0 motor fibres are intact) and very much worse than in motor neurone disease (where sensoby afferent fibres are unaffected).

The changes in the skeletal muscle were constant except in their degree, which varied. Small groups of atrophied muscles suggested denervation and very characteristic was the extreme atrophy of the muscle fibres in atrophic groups. 유 Sometimes only sarcolemmal nuclei within $a \stackrel{2}{\Rightarrow}$ sarcolemmal membrane could be identified, giving a spurious impression of multinucleated $\vec{\supset}$ giant cells. Inflammatory cells were very rarelyọ seen and the muscle fibres never showed any changes of a myopathy or of a dystrophy. A constant finding in our cases was atrophy ofo muscle spindles, with thickening of the capsule and fibrous tissue proliferation within theo capsule. Similar changes have been reported in several series of muscle biopsies from patients은 with various forms of peripheral neuropathy and 7 anterior horn cell degeneration (Lapresle and Milhaud, 1964; Cazzato and Walton, 1968; N Patel, Lalitha, and Dastur, 1968). Peroneal N 
muscular atrophy has not been specifically mentioned in any of these reports, but it is clear that this degenerative change in muscle spindles may be present in other forms of chronic neuropathy, and appearances very similar to those in our cases were found by Lapresle and Milhaud (1964) in a muscle biopsy from a case of porphyria. We have not found spindle abnormalities in biopsy or post mortem material from cases of motor neurone disease or Werdnig-Hoffmann disease, and we suggest that spindle atrophy occurs only in mixed motor and sensory neuropathies, where there is both afferent and efferent denervation of the spindle fibres.

We are grateful to Dr. C. E. C. Wells for his clinical summary of case 1 and to Dr. D. E. B. Powell who performed the necropsy and kindly sent the pathological material. For the use of clinical records of cases 2,3 , and 4 we thank the physicians and surgeons of the United Oxford Hospitals.

\section{REFERENCES}

Alajouanine, Th., Castaigne, P., Cambier, J., and Escourolle, R. (1967). Maladie de Charcot-Marie. Presse Médicale, 75, 2745-2750.

Aran (1855). De l'atrophie musculaire progressive. Gazette des Hôpitaux Civils et Militaires, 28, 293-294.

Bamberger, H. (1860). Bemerkung über progressive Muskelatrophie. Oesterreichische Zeitschrift für praktische Heilkunde, 6, columns 101-110.

Cazzato, G., and Walton, J. N. (1968). The pathology of the muscle spindle. Journal of Neurological Sciences, 7, 15-70.

Charcot, J.-M., and Marie, P. (1886). Sur une forme particulière d'atrophie musculaire progressive souvent familiale débutant par les pieds et les jambes et atteignant plus tard les mains. Revue de Médecine, 6, 97-138.

Péjerine, J., and Armand-Delille, P. (1903). Un cas d'atrophie musculaire, type Charcot-Marie, suivi d'autopsie. Revue Neurologique, 11, 1198-1201.
Eichhorst, H. (1873). Ueber Heredität der progressiven Muskelatrophie. Berlin klinische Wochenschrift, 10, 497499, 511-514.

Eulenburg, A. (1871). Ueber successive Auftreten diffuser Muskelerkrankungen bei Geschwistern. Virchows Archiv für pathologische Anatomie und Physiologie und für klinische Medizin, 53, 361-370.

Friedreich, N. (1873). Über progressive Muskelatrophie, über wahre und falsche Muskelhypertrophie. Hirschwald: Berlin.

Herringham, W. P. (1888). Muscular atrophy of the peroneal type affecting many members of a family. Brain. 11, 230236.

Lapresle, J., and Milhaud, M. (1964). Pathologie du fuseau neuro-musculaire. Revue Neurologique, 110, 97-122.

Marinesco, G. (1894). Contribution à l'étude de l'amyotrophie Charcot-Marie. Archives de Médecine Expérimentale et d'Anatomie Pathologique (Paris), 6, 921-965.

Marinesco, G. (1928). Contribution à l'étude anatomoclinique de l'amyotrophie Charcot-Marie. Revue Neurologique, 35, II, 543-561.

Oppenheimer, Z. (1855). Ueber progressive fettige Muskelentartung. In Habilitationsschrift Universität Heidelberg. Mohr: Heidelberg.

Ormerod, J. A. (1884). Muscular atrophy, after measles, in three members of a family. Brain, 7, 334-342.

Osler, W. (1880). On heredity in progressive muscular atrophy as illustrated in the Farr family of Vermont. Archives of Medicine, N. Y., 4, 316-320.

Patel, A. N., Lalitha, V. S., and Dastur, D. K. (1968). The spindle in normal and pathological muscle. An assessment of the histological changes. Brain, 91, 737-750.

Pette, H. (1924). Zur Pathogenese der neurotischen Muskelatrophie. Zeitschrift für die gesamte Neurologie und Psychiatrie, 92, 324-345.

Sainton, P. (1899). L'Amyotrophie, Type Charcot-Marie. G. Steinheil: Paris.

Schultze (1884). Ueber eine eigenthümliche progressive atrophische Paralyse bei mehreren Kindern derselben Familie. Berlin klinische Wochenschrift, 21, 649-651.

Tooth, H. H. (1886). The Peroneal Type of Progressive Muscular Atrophy. Lewis: London.

Tooth, H. H. (1887). Recent observations on progressive muscular atrophy. Brain, 10, 243-253.

Virchow, R. (1855). Ein Fall von progressiver Muskelatrophie. Virchows Archiv für pathologische Anatomie und Physiologie und für klinische Medizin, 8, 537-540. 